\title{
"lls profitent": fantasmas do presente nos processos colaborativos em tempos de práticas sociais, um estudo de caso
}

José Cirillo*

http://dx.doi.org/10.22409/poiesis. 1829.057072

\begin{abstract}
RESUMO: O artigo discute como os modos de aproximação das práticas estéticas sociais, em especial as colaborativas, são como estratégias de revitalização da arte contemporânea. Foca seu estudo na análise de algumas características do processo criativo de Piatan Lube, nas quais são verificados o que aqui é definido como fantasmas que assombram os artistas na prática efetiva de projetos compartilhados com comunidades. Partimos da ideia de que existem alguns fantasmas que assolam a coerência dos processos criativos colaborativos: o fantasma do autor externo; o fantasma da ausência de coerência interna do projeto e o fantasma da ficção como realidade. A partir desses três pontos, analisamos aqui o primeiro do fantasmas, o da autoria externa, nessa busca de coerência interna das propostas do artista Piatan Lube, em sua experiência como escultor social.
\end{abstract}

PALAVRAS-CHAVE: arte colaborativa, autoria externa, arte contemporânea, Piatan Lube, escultura social

RESUMEN: El artículo discute cómo los modos de aproximación de las prácticas estéticas sociales, en especial las colaborativas, son como estrategias de revitalización del arte contemporáneo. Enfoca su estudio en el análisis de algunas características del proceso creativo de Piatan Lube, en las que se verifican lo que aquí se define como fantasmas que rondan a los artistas en la práctica efectiva de

\footnotetext{
* José Cirillo é Professor Permanente do Programa de Mestrado em Artes (PPGA/UFES) e do Programa de Mestrado em Comunicação (PPGCS/UFES) e artista plástico. Possui graduação em Artes pela Universidade Federal de Uberlândia (1990), mestrado em Educação pela Universidade Federal do Espírito Santo (1999), doutorado em Comunicação e Semiótica pela Pontifícia Universidade Católica de São Paulo (2004) e Pós-doutorado em Artes pela Faculdade de Belas Artes da Universidade de Lisboa. Atualmente é Professor Associado da Universidade Federal do Espírito Santo. É Editor da Revista Farol (PPGA-UFES) e membro do Conselho Científico da Revista Estúdio e da Revista Manuscrítica. E-mail: josecirillo@hotmail.com.
} 
proyectos compartidos con comunidades. Nos pareció de la idea de que existen algunos fantasmas que asolan la coherencia de los procesos creativos colaborativos: el fantasma del autor externo; el fantasma de la ausencia de coherencia interna del proyecto y el fantasma de la ficción como realidad. A partir de estos tres puntos, analizamos aquí el primero de los fantasmas, el de la autoría externa, en esa búsqueda de coherencia interna de las propuestas del artista Piatan Lube, en su experiencia como escultor social.

PALABRAS CLAVE: arte colaborativo, autor externo, arte contemporáneo, Piatan Lube, escultura social

\title{
Deambulações preliminares
}

\begin{abstract}
O pós-modernismo, que tende tanto para o antielitismo como para o antiuniversalismo, vive assim uma certa tensão entre seus valores políticos e filosóficos. Ele procura resolver isso ignorando o universalismo e voltando para um tipo de particularismo pré-moderno, mas agora para um particularismo sem privilégio, o que equivale a dizer para uma diferença sem hierarquia. (EAGLETON, 1998, p. 111-112)
\end{abstract}

O engajamento social da arte parece efetivamente estar se voltando para práticas que despertem a atenção para procedimentos estéticos com mais articulações com os conflitos da sociedade e das cidades na contemporaneidade. Vale destacar que este direcionamento não é novo e que, mesmo nas vanguardas históricas, via-se, de modo geral, um produção voltada para as questões que envolviam um cultura de conflitos políticos, econômicos, culturais e sociais; mas também vale atentar que esses parâmetros estavam pautados na crise daquelas culturas tida como hegemônicas e norteadoras (em uma visão colonialista) dos parâmetros culturais mundiais, seja por imposição, seja por imitação. Este foco centralizado que se dilui na atualidade resulta em experiências fora dos centros, nas chamadas periferias, mas que efetivamente parecem mais próximas de dilemas sociais de culturas apagadas.

Falamos em apagamentos e não em invisibilidades. Invisível é aquilo que existe, mas que ninguém vê. Apagamento é um ato intencional de quem domina os meios de circulação e que intencionalmente opta por não dar visibilidade ao que ocorre. A ideia de uma cultura 
hegemônica que conduziu a modernidade como uma utopia globalizante cede lugar gradativamente à percepção de outros modos de fazer; em especial, outros modos de fazer arte, ou processos estéticos coletivos que coloquem em cheque os sistemas herméticos que ainda insistem em dominar o campo artístico, em especial nas instituições demarcadoras do campo. Essas práticas, aparentemente novas, estão em grande parte voltadas para estéticas coletivas (colaborativas, relacionais ou participativas) que têm como foco um certo papel social da arte, embora poucas efetivamente têm seu norte nas demandas sociais de fato - aqui vale lembrar que, por questões de suas características culturais, nos parece que a arte latino-americana, embora institucionalmente apagada por interesses de eixo do sistema de poder geograficamente centrados em uma ideia de norte dominador e de um sul colonizado, tenha articulado isto já há um certo tempo. Porém, vale lembrar também que, em termos cosmológicos, a ideia de norte e sul está pautada em um posicionamento do planeta no universo que não encontra hierarquia entre acima ou abaixo, pois a dinâmica rizomática do cosmo não demarca esses pontos cardiais como os trabalhamos. Essa ordem geográfica interna ao planeta estabelece um acima (norte) e abaixo (sul) que no universo não tem relevância. Portanto, estamos em um sistema de verdades geográficas, políticas e culturais artificial. Vivemos ficções como realidade. Essas ficções, tidas e confundidas como realidade, parecem estar tendo sua percepção aflorada e, automaticamente, nos levando a reestruturar o pensamento sobre práticas vivenciais que nos levam, no campo da arte, a pensar estéticas voltadas ou relacionadas ao social ou pautadas em enfrentamentos das práticas sociais correntes.

Para Claire Bishop (2008, p. 147), o panorama que envolve as chamadas práticas estéticas relacionadas com o social, em especial aquelas que, diferentemente das práticas relacionais, têm seu foco centrado em demandas sociais e em enfrentamentos estéticos em grupos sociais, geralmente em espaços periféricos urbanos, "[...] socialmente colaborativas forma a princípio o que temos de avant-garde nos dias de hoje: artistas que usam situações sociais para produzir projetos desmaterializados, antimercadológicos e politicamente engajados, que levam adiante o apelo modernista de mesclar a arte à vida." Na sequência das reflexões da autora, podemos pensar sobre uma certa dualidade investida sobre os artistas que enveredam neste campo contemporâneo da arte; enfrentam, de um lado, uma descrença institucional nesta interface colaborativa, dada a uma certa marginalidade associada a essas produções; de outro, aproximações demasiadamente romantizadas que as veem como uma estratégia 
de resistência, uma última fronteira aos determinismos hegemônicos de uma cultura global dominante (ou que se diz como tal) e de práticas mercantilistas a que a arte está submetida.

Digo romantismo por ser uma ideia que em si parte, de fato, de uma utópica possibilidade de transformação do mundo pela arte, que assola o meio desde os ideais da maioria das vanguardas históricas. Os avanços tecnológicos ou os discursos contemporâneos sobre igualdade social têm sido construídos sobre pressupostos teóricos também generalizantes e que parte de concepções hegemônicas - talvez mudando ligeiramente que é o centro irradiador da nova ideologia globalmente generalizante - que continuam revelando processos coloniais em uma sobremodernidade generalizante e excessivamente particularizada, a ponto de padronizar o afastamento crítico da percepção coletiva social. Algo que parece ir na contramão dos ideais revolucionários da Paris de 1968, quando a Escola de Belas Artes é tomada por artistas que iniciam um processo de panfletagem que revela uma intencionalidade poética para crítica e transformação social. Fato que Bishop (2012) parece ilustrar bem ao escolher um desses cartazes para abrir um capítulo de seu livro Artificial Hells. Nesse cartaz do Atelier Populaire, de 1968, a conjugação do verbo participar indica uma atitude político-conceitual que sintetiza a proposta de transformação social em curso naquele momento, e que nos parece ser o horizonte do provável na arte colaborativa.

No cartaz em questão, mais que a imagem, os signos verbais revelam uma intencionalidade transformadora e uma tendência poética para o coletivo. A conjugação do verbo "participar" segue regular em todos os pronomes pessoais do singular e nos dois iniciais do plural, porém é interrompida na terceira pessoa do plural, quando o verbo "participar" é alterado para "ganhar" ou "lucrar".

O benefício da participação de cada um é coletivo. Todos se beneficiam. O que politicamente parecia indicar a relevância da junção de forças individuais para que o efetivo social se beneficiasse com as ações em curso naquele momento transcende a materialidade do discurso perceptível. O jogo semiótico se estabelece. O resultado da ação de cada um somente se conclui na dimensão do outro coletivo. Eu e os outros não como uma dicotomia moderna, mas como faces complementares de um mesmo jogo no qual todos se beneficiam.

É deste ponto que partem, especificamente, as reflexões apontadas neste texto que se segue: em que medida as práticas colaborativas, em curso na arte contemporânea, efetivamente 
je perticipe tu particires Q participe nous paritcipons vous paricicer ils pegitent

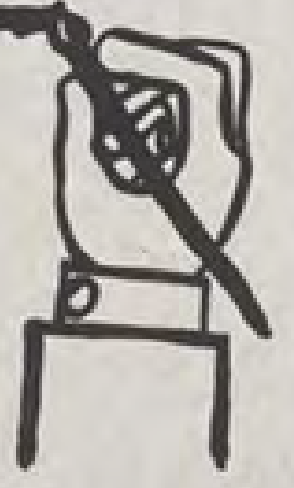


conjugam essa terceira pessoa do plural como síntese da conjugação de saberes e fazeres sociais, políticos, econômicos e estéticos (para nomear alguns) que "romanticamente" são incorporados por muitos artistas que se aventuram por este campo colaborativo? Como a questão da autoria externa é processada no interior do projeto poético de artistas que se dispõem a serem facilitadores nesses processos sociais? Quando efetivamente ela, a autoria, é compartilhada para além do fazer do objeto em processo? Em que dimensão essas práticas sociais colaborativas se diferenciam de experiências participativas quando nos referimos ao lugar do outro? O I/s profitent - para tomar para nós um pouco do diálogo com o grupo do Atelier Populaire - se estabelece nessas obras?

Não temos a pretensão generalista, mesmo porque ela, a generalização, não mais cabe na contemporaneidade, não é possível falar ou construir verdades; buscamos possibilidades e retratamos angústias de mentes criadoras em seu processo criativo. Trabalha-se na pluralidade de cada caso, nas recorrências possíveis que apontam pontos de convergências, mas não se constituem como verdades absolutas - mesmo porque essas ruíram como torres imperialistas, estrategicamente fragilizadas em sua estrutura, derrubadas e em cuja poeira, enterraram-se as verdades contemporâneas da hegemonia e dos sistemas totalizantes que, embora agonizantes, tentam retomar, inutilmente, retomar o lugar que não mais lhes pertence.

Assim, a análise aqui se dá a partir de um estudo de caso, em particular dos documentos do processo de criação da intervenção Araçá-Oca (2014-2015). As obras desse jovem artista capixaba ${ }^{1}$ tem sido referenciais nos compartilhamentos reflexivos sobre o lugar do artista e das práticas de arte que buscam uma mediação com o social e, consequentemente, o político em tempos discursos de descentralização da autoria, de fragmentação dos discursos e mesmo de autonomia das artes. A partir das considerações iniciais sobre as obras relacionadas ao processo criativo desse artista, podemos inferir que três fantasmas parecem pairar sobre esses conceitos em uma produção artística tida como colaborativa: o fantasma do autor externo que desmonta a ideia de um projeto autógrafo e reconfigura a noção de autoria nas obras colaborativas, bem como em seus desdobramentos; o outro fantasma, a ausência de coerência interna do projeto, pode comprometer a capacidade interna do projeto estético da ação de ser acionada por qualquer um dos autores envolvidos. Essa coerência, como um nó de rede, pode ser acionada de qualquer ponto e por qualquer um envolvido na proposta, mas esta capacidade coletiva pode ser comprometida em projetos ficcionalmente colaborativos. Nessa 
ficcionalidade configura-se o terceiro fantasma: uma espécie de ficção de realidade na qual o artista acredita estar efetivamente construindo uma proposta colaborativa que reflita mais os anseios compartilhados do coletivo que suas angústias internas como poeta da forma. Vamos tentar tratar desses fantasmas a partir da produção de três projetos poéticos específicos de Piatan Lube, nos quais é predominante um dos tipos desses espectros conceituais.

\section{O fantasma do autor externo: o medo e o complexo autoral}

Araçá-Oca (2014-2015) é uma proposta de trabalho colaborativo com (ou em) uma comunidade quilombola urbana na região metropolitana da Grande Vitória, no Espírito Santo. Consistia conceitualmente na criação de um espaço de mediações entre as ideias de paisagem e memória do artista com a memória coletiva da comunidade, interagindo sua matrizes indígenas e africanas. Juntamente com a comunidade, iriam criar-se um espaço urbano de convívio coletivo, uma espécie de anfiteatro e sala construídos com plantas de araçá (pequena goiabeira selvagem); esses espaços de arquitetura natural exigiriam alguns anos de cuidados e de podas para se constituírem efetivamente como objeto na paisagem da comunidade, exigindo entrega de Lube e da comunidade para sua efetivação. Assim, a proposta originou-se de imersões de Lube na comunidade e do diálogo com os desejos coletivos (dele e da comunidade).

Esse enfrentamento coletivo exigiu que todos se colocassem como agentes determinantes dos destinos da proposta, passando, consequentemente, por uma descaracterização do lugar autoral do artista. Instaurou-se aí o primeiro fantasma das práticas colaborativas de Lube, com o qual ele não soube lidar. Acompanhamos o processo de criação da intervenção, assim como os conflitos colocados em Lube a partir da verificação disto, de sua não autonomia sobre a intervenção inicialmente proposta por ele; seguimos suas marcas processuais até onde ele conseguiu se constituir e verificar-se como autor que não queria abrir mão de sua autonomia como artista criador. A impossibilidade de perceber que essa autonomia estava fraturada vai ser o estopim para que a obra não tenha se materializado.

A proposta do artista, até então com forte discurso colaborativo, enfrentou um embate com uma estrutura social edificada em torno de uma cultura tradicional, de uma comunidade de resistência e fortemente estruturada em uma perspectiva social e organizacional predominantemente coletiva e centrada em uma matriz matriarcal de base africana e na prática efetiva de 
uma memória coletiva. Neste cenário apresentado, uma crise foi instaurada na identidade do artista, exposto a uma proposição conjunta em uma comunidade tradicional que não reconhece identidades individualmente instituídas, e na qual a rede de afetos está estabelecida sobre uma matriz predominantemente coletiva.

Nessa comunidade pode-se perceber, em estado nascente e vivo, aquilo que Maurice Halbwachs (1990) considera como memória coletiva e que, segundo o autor, mantém do passado o que ainda está vivo, ou que é capaz de viver na consciência do grupo; este grupo a mantém como sendo uma experiência recém vivida pelos sujeitos do aqui e do agora. Destitui-se o conceito de eu-individual e institui-se o de alteridade. Esta reflexão é importante para se compreender como Lube vai deparar-se com um fato novo em sua relação com as comunidades nas quais se predispõe a mediar intervenções urbanas de base colaborativa: a necessidade de despir-se de si e buscar encontrar pontos de mediação possíveis nesse novo contexto colaborativo em curso, necessidade primordial no projeto poético de ações compartilhadas efetivamente no campo coletivo das relações sociais. Um fantasma que não conhecia e que não estava preparado para o embate.

Para tal afirmativa, parte-se do princípio de que uma obra colaborativa implica em despir-se de concepções prévias e autógrafas do que sejam as relações arte e vida; artista e transeunte; autor e leitor; e, sobretudo, faz-se necessária uma revisão da própria memória do chamado artista (no caso, Lube) e de sua noção de compartilhamento efetivo no corpo social. Mas, essa não é, certamente, uma tarefa simples nem mesmo fácil aos que a ela se propõem. Rotineiramente, cai-se em armadilhas que a mente do artista prepara, ao longo do ato criador dessas obras colaborativas, e que está condicionada pelas noções tradicionais de arte e pela lógica cartesiana das relações afetivas e autorais.

Para tentar discutir um pouco sobre tais conflitos de pertencimento, tomamos aqui algumas evidências enunciativas expressas no processo criador da proposta intervencionista AraçáOca (2014-2015), um projeto de residência artística na comunidade tradicional de Araçatiba (Viana, ES), uma comunidade de matriz híbrida entre as culturas negra, indígena e cristã2. Esse é o cenário social e cultural da comunidade na qual Araçá-Oca tentou se instaurar a partir de julho de 2014, mas não se efetivou como proposta inicialmente, desaparecendo totalmente da paisagem da comunidade. Sua falência como intervenção resultou, em parte, dos conflitos do artista com a noção de compartilhamento autoral do projeto. 
Se pensarmos em termos mais funcionais, a ação resultou em uma intervenção temporária que não correspondeu ao que esperava o projeto de Lube. Hoje, ainda restam, nos quintais da comunidade, algumas das 2.000 mudas de araçás, agora árvores, que se destinavam ao projeto. A grande maioria delas morreu ao longo da espera por um destino na comunidade, enquanto as que sobreviveram tiveram seus destinos determinados por aqueles que inicialmente eram seu cuidadores até que virassem parte da futura obra. Podemos dizer que a comunidade e o seu conceito de coletividade instauraram-se como um fantasma que assombrou o processo da artista, o que vai ser evidenciando em diálogos com seus documentos de processo (Salles, 1998), aqueles gerados por Lube ao longo dos primeiros meses.

Não há necessidade de que o artista, como facilitador de uma ação colaborativa em uma comunidade, seja nativo desse entorno, mas é fundamental que se coloque aberto para as mediações necessárias para que se instaure um certo nível de compartilhamento que permita acessos ao nós da rede cultural instaurada, para que ele, o mediador estético ou o facilitador do processo plástico, possa compartilhar, mesmo que provisoriamente, um processo de edificação sensível de compartilhamentos afetivos e materiais na comunidade.

Piatan Lube não era totalmente alheio à realidade da comunidade, embora externo a ela. Ele nasceu em Minas Gerais, mas mudou-se muito cedo para a zona rural de Viana, ES. Portanto, vizinho territorial da comunidade de Araçatiba, compartilhando parte da dimensão mais geral da cultura rural local. O projeto de residência na comunidade foi articulado conjuntamente entre a coordenação da Residência - feita pelo Laboratório de Extensão e Pesquisa em Arte da UFES, a comunidade e o artista. Lube, como dito antes, revela uma tendência em seu projeto poético ao trabalho colaborativo, vindo de experiências interessantes neste sentido, além de várias participações e vivências em coletivos de arte, ao que se soma o fato de, por ser da região, ter afinidade com a vida simples do campo e com as acomodações monásticas disponíveis na comunidade, o que seria, aparentemente, características fundamentais para o sucesso da atividade.

O projeto Araçá-Oca foi apresentado cinco meses após o início dos contatos e da vivência de Lube com a comunidade. Desde os primeiros contatos, o artista comenta em sua correspondência com a coordenação do projeto: 
[...] estou impressionado com a força de araçatiba.

Muita coisa florida nascendo em mim depois de um primeiro encontro.

Tenho algumas coisas fortes para conversarmos. e imagina os próximos encontros com a comunidade....

possibilidade ....

01- O rio Morto (plantio de araçás.... no seu percurso....)

02 - A argila (as casas de barro) Imagina um mutirão com os moradores na reconstrução de uma casa de pau-a-pique?

onde os moradores que são os arquitetos, os senhores das formas e técnicas de construção. Uma área que almejo, mas desconheço profundamente suas técnicas. Ali onde eles me disseram que havia várias casas de barros e hoje não tem mais nenhuma ....

03 - Redesenhar as plantas baixas das casas que não existem mais com araçá.

TIBA-

Significados de Tiba:

1. Tiba

1- Significa: cheio; atulhado.

2 - (no nordeste) - grande; volumoso; grosso; valentão.

3 - (gíria)- lugar onde há muitas pessoas juntas.

(Lube, 2014) ${ }^{3}$

Observa-se, neste comentário na mensagem eletrônica, a origem da imagem geradora do projeto artístico: a casa. Verifica-se, também, o interesse pelo compartilhamento com os moradores dos saberes e fazeres da comunidade, o que é uma ação esperada em um projeto colaborativo. A imagem da edificação (casa) é uma imagem mental forte na comunidade que, por ser de matriz quilombola, tem nesses elementos de propriedade uma clara simbologia de poder. Na verdade, a comunidade se origina em torno de uma edificação, a casa da Santa Nossa Senhora d'Ajuda, a Igreja Matriz da comunidade. Assim, Lube em alguns meses já tinha conseguido inserir em si a importância dessa matriz imagética da comunidade: a casa.

$\mathrm{Na}$ análise desse documento de processo, pode-se perceber que ele já compartilha com eles o mito do nome da localidade (TIBA, a filha do Cacique morta de amor, segundo a comunidade); 
mas Lube lhe apresenta outras possibilidades, tratando o termo como se em um dicionário. Aqui, parecem reconstruir juntos os dados conceituais necessários para o avanço da intervenção - pelo menos isto parece sugerido no corpo da mensagem. Há uma clara intenção colaborativa, o que se verifica em trecho de outra mensagem: "[...] exige-se em mim que seja um trabalho colaborativo por inteiro.... O caminhar pelas ruas, o conversar com as pessoas, o tentar conhecer mais sobre eles e sobre o local ajuda-o a esboçar um projeto da intervenção.

Embora manifeste claramente uma intencionalidade colaborativa, é exatamente neste ponto, o esboço do projeto, que os enfrentamentos do ego do artista começam a afastar-se da rede de afetos e da simultaneidade afetivas necessárias para o desprendimento do conceito de propriedade privada inerente ao tradicional de autoria, para um conceito compartilhado de autores externos. O fantasma da autoria assombra Lube, não seu lugar de autor, mas a ideia de ter efetivamente um autor externo a si (a comunidade). Um outro autor, alheio a si, perturba-lhe o pensamento e suas reflexões sobre o projeto começam a distanciar-se de uma real construção colaborativa, embora permaneça a vontade da prática estética socialmente instituída. Nos escritos de Lube, a forma "casa de barro" vai surgindo, mas ainda há uma expectativa de compartilhar, de ouvir e envolver o outro no seu processo criativo ("os senhores da forma"), aqueles que conhecem o que ele não domina:

\footnotetext{
A argila (as casas de barro) Imagina um mutirão com os moradores na reconstrução de uma casa de pau-a-pique?

onde os moradores, que sãos os arquitetos, os senhores das formas e técnicas de construção. Uma área que almejo mas desconheço profundamente suas técnicas. Ali onde eles me disseram que havia várias casas de barros e hoje não tem mais nenhuma ....
}

03 - Redesenhar as plantas baixas das casas que não existem mais com araçá. (Lube, 2014) ${ }^{4}$

No trecho de outra correspondência com a coordenação do programa de residência, o projeto parece caminhar na direção da mediação do seu lugar e o do lugar dos moradores, especialmente os mais antigos. O propósito de retrabalhar as casas de barro e a memória da ocupação negra na comunidade, desde os jesuítas, se afasta, embora o artista não deixe escritos ou qualquer anotação visual que permita entender como se deu o novo projeto que se efetiva quando ele finalmente apresenta-o para a coordenação da Residência: Araçá-Oca. 
Percebe-se que, ao definir a obra, ele se afasta da atual matriz negra da comunidade, em detrimento da origem indígena do nome: a oca e o araçá. Porém, esse espaço também parece estar relacionado a espaços de compartilhamento em comunidades mais próximas daquilo que Lévi Strauss chamou de selvagem: tanto na base da tradição negra africana, quanto na dos nativos indígenas da região, os espaços de compartilhamento de memórias eram centrais na aldeia. O que aparentemente indica uma certa coerência com a memória local. Porém, o projeto da obra vai tomando particularidades que começam a afastar o papel autoral do outro comunitário.

À medida que o projeto ganha corpo na mente e nos cadernos de anotações de Lube, os autores externos da comunidade, subjetividades afetivas do projeto, vão sendo instalados não como grupo de afetos, mas como força de trabalho pelo, agora, artista. Eles, na comunidade, vão cuidar das mudas, cavar as covas, regar as plantas, fazer podas como determinado etc., tudo necessário para que o espaço como pensado pelo artista (Lube) se edifique em alguns anos. A obra, agora pensada somente nos projetos por Lube, buscava ser uma arena de memórias: uma casa cujas paredes se formariam no entrelaçamento das mudas de araçás ao longo dos anos, um trabalho de topiaria que criaria uma espécie de monumento à comunidade e sua história. Caberia à comunidade cuidar delas, qual jardineiro. Mas, a forma do objeto não mais Ihes pertencia, tal qual o jardim não pertence ao jardineiro. Nem mesmo em sua localização.

Essa é uma evidência de como o fantasma da autoria compartilhada foi expurgado por Lube e, em seu lugar, instaurou-se a romântica noção de autonomia do autor e da arte. Marcas indiciais disto podem ser percebidas no projeto que vai se finalizando. A colaboratividade como prática estética é uma aproximação contemporânea na qual parece que a autonomia do artista e da obra está superada, ou pelo menos deveria estar.

Esse processo de retomada do autor e da autonomia criadora do artista e da obra vai se materializar nas anotações seguintes de Lube. Embora a escolha do local da intervenção tenha sido decidido com a comunidade (a área livre em frente à escola e que a comunidade pleiteava junto ao poder público que fosse uma praça), sua ocupação desconsidera os fluxos diários no espaço escolhido. Antes de ser escolhido pelo artista, esse espaço era vivido pela comunidade. Esta apropriação unilateral do espaço fica muito evidente se observarmos a fotografia de registro que o artista faz do processo de demarcação da área da obra. 


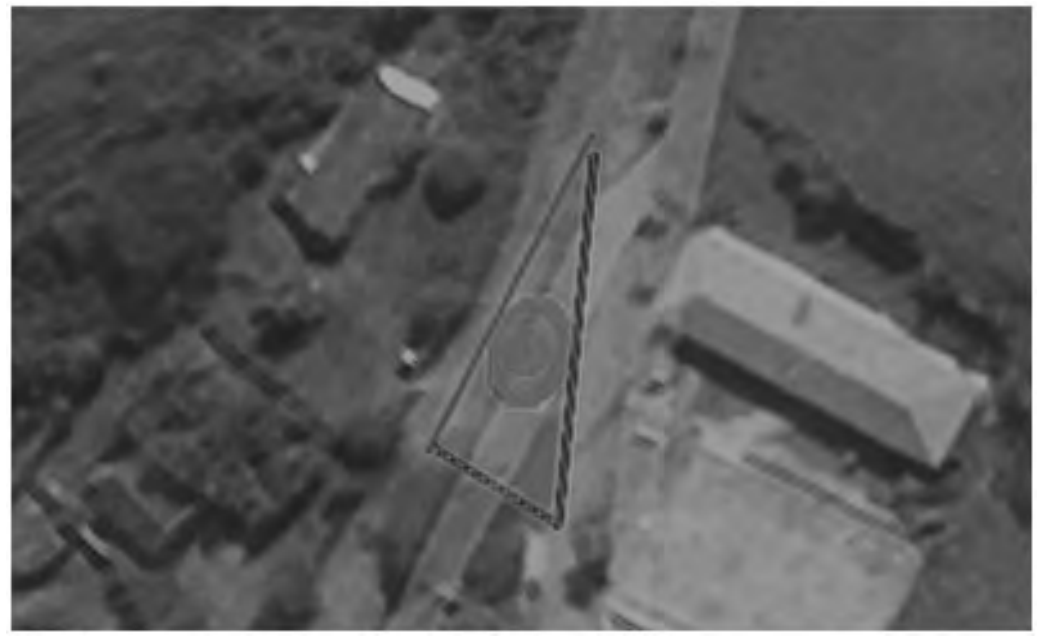

Projeção em vista aérea do local de instalação. Arquivo digital, 2014.

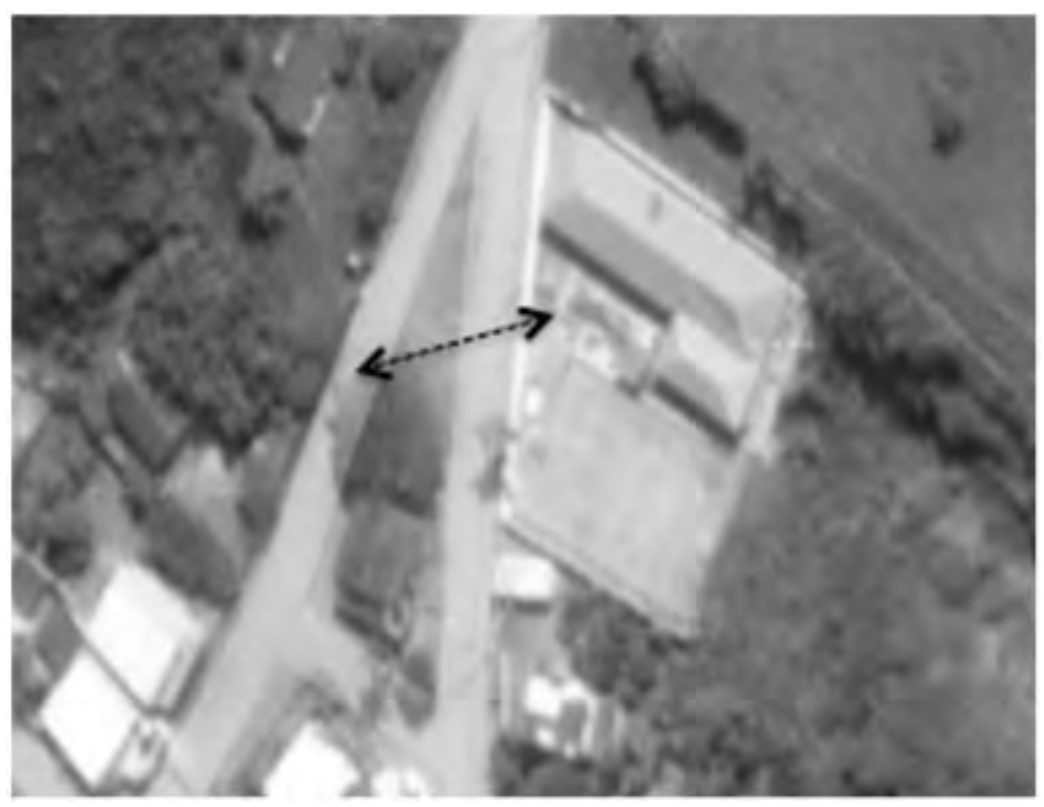

A seta pontilhada indica o fluxo de adultos e de crianças ao se dirigirem para ou da escola. (Fonte: Banco de Dados Piatan Lube - LEENA/ UFES - Foto: Piatan Lube) 
Pode-se observar que a oca proposta interrompe o percurso dos moradores em sua relação com a escola. O artista foi alertado, mas parece ter ignorado, mesmo que durante o período de marcação do terreno esse fluxo interrompido pudesse ser percebido.

Tanto nas anotações do caderno do artista, quanto nas imagens da Figura 3, pode-se perceber que a obra põe-se no caminho que as crianças percorrem diariamente para a escola; verifica-se que o artista, aqui modernamente reinstaurado, desconsidera o fato e segue com a obra que intervirá nos caminhos do outro - uma espécie de Titled Arc (1981), de Richard Serra, que interrompe fluxos, embora a intenção da obra de Serra fosse exatamente esta, o que não é o caso de Araçá-Oca. Esta intencionalidade não está verificada no processo de criação da obra. Isto posto, parece que amadurece um afastamento das intersubjetividades esperadas no trabalho colaborativo que estava em curso. Esta afirmativa pode ser evidenciada e o argumento anticolaborativo ser reforçado em outras anotações do artista sobre este momento:

Construí uma marcação e demarcação da área primária da ARAÇÁ-OCA.

OBS 02: Acredito que poderíamos prever, para um número mínimo de pessoas da comunidade, um retorno quando o mutirão de aplainamento. Segundo considerações de alguns deles e do Sr. Gentil. Gerar renda imediata? ele falou que aumenta a reverência e a participação, se pensarmos nisso.

$(\text { Lube, 2014) })^{5}$

Os verbos na primeira pessoa do singular, "construí" ou "acredito", e a ideia de que a remuneração de um "número mínimo de pessoas" tornaria significante a participação indica que, embora esteja tendo ajuda da comunidade, esta parece ter sido relocada como força de trabalho, em detrimento de uma coautoria anteriormente expressa ou desejada. Percebe-se que a relação com o compartilhamento na comunidade está caminhando para o afastamento do estar de modo afetivo no projeto, e parece se deslocar de uma ação colaborativa para uma relação de trabalho remunerado. A comunidade se tornava mão de obra. Aqui, o possível coautor, ou autor externo afetivamente instaurado, parece ceder lugar ao participante, ou ao contratado para executar um trabalho.

Assim, parece que podemos afirmar que a autoria externa e colaborativa foi vencida por um desvio para o artista, em detrimento da morte do artista como mediador, como [inter]ator (aqui tratados como fantasmas da pós-autonomia que assolam a tradição da autoria como 

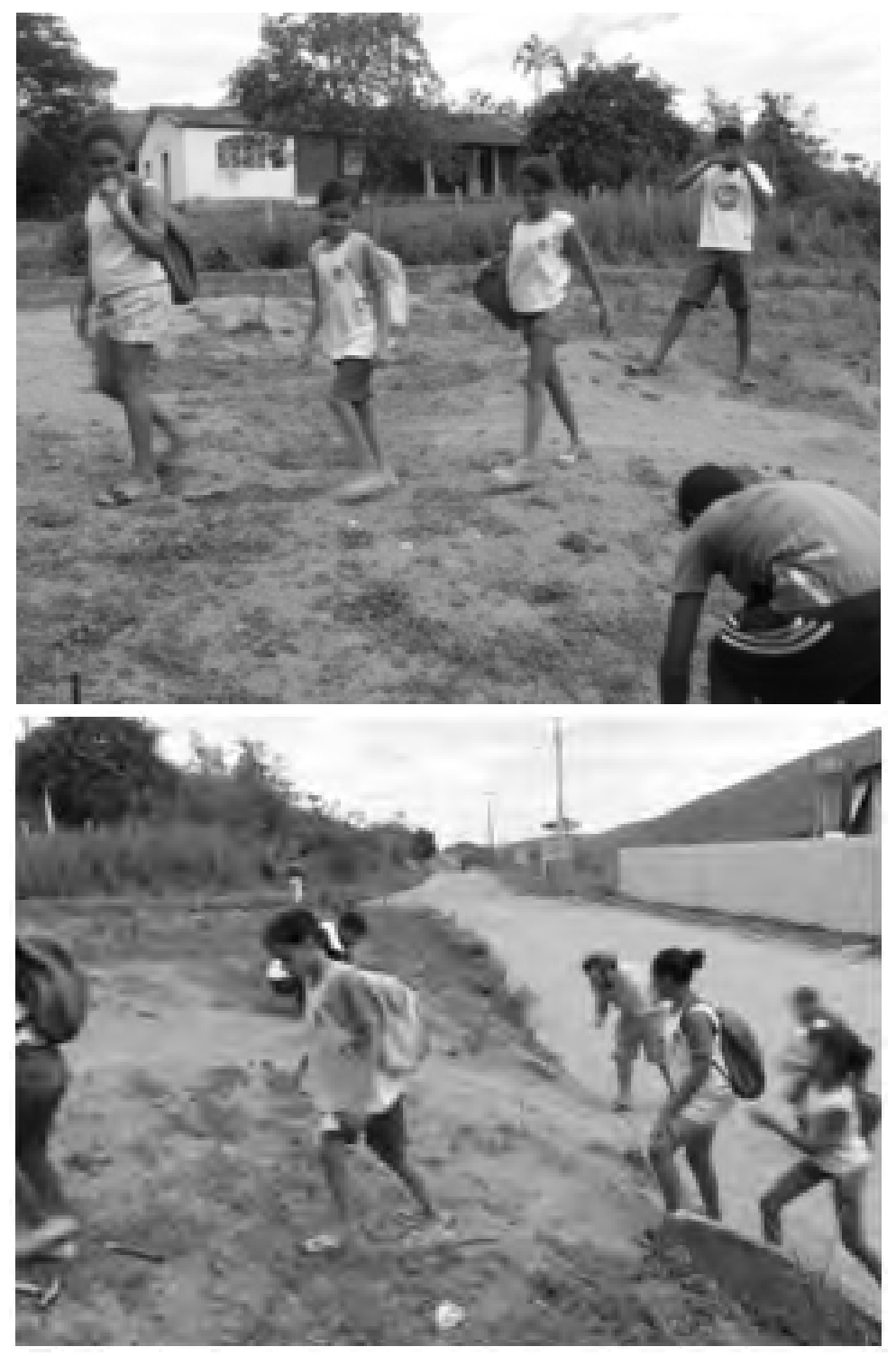

Fluxo dos alunos ao saírem da escola cruzando a área em demarcação para a obra. Arquivo digital, 2014.

(Fonte: Banco de Dados Piatan Lube. LEENA/ UFES - Foto: José Cirillo) 
propriedade privada). Ao se aproximar do projeto final da obra, Lube parece afastar-se do desejo do outro. A possibilidade de criatividade entre os indivíduos parece estar sendo quebrada e a rede de afetos parece ruir definitivamente. Araçá-oca foi apagada, coberta pelo manto do esquecimento, pois não se configurou como um projeto coletivo e afetivamente compartilhado, não se materializou como um projeto colaborativo - único modo como ele poderia se instaurar naquela comunidade. Lube caiu na armadilha da vaidade do artista. Ressuscitou o autor e expurgou o fantasma da autoria compartilhada.

Podemos afirmar que o "lls profitent" não se instaurou.

\section{Referências}

BISHOP, Claire. Artificial Hells: Participatory Art and the Politics of Spectatorship. Londres; Nova York: Verso, 2012.

BISHOP, Claire. A virada social: colaboração e seus desgostos. Tradução de Jacson Campelo. Concinnitas, Rio de Janeiro, v. 1, n. 12, jul. 2008

EAGLETON, Terry. As ilusões do pós-modernismo. Tradução de Elisabeth Barbosa. Rio de Janeiro: Zahar, 1998.

HALBWACHS, Maurice. A memória coletiva. São Paulo: Vértice, 1990

SALLES, Cecília. Gesto Inacabado: processo de criação artística. São Paulo: Annablume, 1998.

\section{Notas}

1 Piatan Lube Moreira é artista plástico e Mestre em Artes pelo Programa de Pós-Graduação em Artes da Universidade Federal do Espírito Santo (2016). Atualmente é pesquisador e articulador comunitário, com projetos e práticas artísticas e ativistas. Artista socialmente engajado e multidisciplinar, nascido em Minas Gerais, no ninho poético do barroco mineiro. Segundo o artista, seu olfato se acostumou aos perfumes do tempo, cheiros de cera de abelha derretida, pigmentos em pó mágicos que viravam homens e plantas, elementos que fazem parte de sua produção artística.

2 Araçatiba tem sua origem em uma fazenda dos jesuítas no Espírito Santo, criada em cerca de 1704, quando das obras iniciais da Igreja de N. Sa. d' Ajuda. No espólio do jesuítas - inventariado no final do século XVIII -, constam, além de todos os demais bens, cerca de 800 negros escravizados. É desse contingente que deriva o grupo de negros que, no final do século seguinte, formou a comunidade de Araçatiba, que permanece como um quilombo urbano na periferia da Região Metropolitana de Vitória.

3 Transcrição de e-mail enviado à coordenação do projeto de Residência Artística em 31 de julho de 2014, quando oficialmente iniciou-se o processo de intervenção do artista na e com a comunidade.

4 Transcrição de e-mail do artista para a coordenação do programa em agosto de 2014.

5 Anotação do artista sobre o processo da obra, enviado em e-mail para a coordenação da residência em setembro de 2014 